\title{
MARSIS radar sounder evidence of buried basins in the northern lowlands of Mars
}

\author{
Thomas R. Watters ${ }^{1}$, Carl J. Leuschen ${ }^{2}$, Jeffrey J. Plaut ${ }^{3}$, Giovanni Picardi ${ }^{4}$, Ali Safaeinili ${ }^{3}$, Stephen M. Clifford ${ }^{5}$, \\ William M. Farrell ${ }^{6}$, Anton B. Ivanov ${ }^{3}$, Roger J. Phillips ${ }^{7} \&$ Ellen R. Stofan ${ }^{8}$
}

\begin{abstract}
A hemispheric dichotomy on Mars is marked by the sharp contrast between the sparsely cratered northern lowland plains and the heavily cratered southern highlands. Mechanisms proposed to remove ancient crust or form younger lowland crust include one or more giant impacts, subcrustal transport by mantle convection, the generation of thinner crust by plate tectonics, and mantle overturn following solidification of an early magma ocean ${ }^{1-7}$. The age of the northern lowland crust is a significant constraint on these models. The Mars Advanced Radar for Subsurface and Ionospheric Sounding (MARSIS) instrument on the European Space Agency's Mars Express spacecraft is providing new constraints on the martian subsurface ${ }^{8}$. Here we show evidence of buried impact basins ranging in diameter from about $130 \mathrm{~km}$ to $470 \mathrm{~km}$ found over 14 per cent of the northern lowlands. The number of detected buried basins $>\mathbf{2 0 0} \mathrm{km}$ in diameter indicates that the lowland crust is ancient, dating back to the Early Noachian epoch. This crater density is a lower limit because of the likelihood that not all buried basins in the area surveyed by MARSIS have been detected. An Early Noachian age for the lowland crust has been previously suggested on the basis of a large number of quasicircular topographic depressions interpreted to be evidence of buried basins $s^{9-11}$. Only a few of these depressions in the area surveyed by MARSIS, however, correlate with the detected subsurface echoes. On the basis of the MARSIS data, we conclude that the northern lowland crust is at least as old as the oldest exposed highland crust. This suggests that the crustal dichotomy formed early in the geologic evolution of Mars.
\end{abstract}

In the immediate post-Viking era of Mars exploration, it was considered that the crust of the northern lowlands might be as young as the plains materials that cover it ${ }^{12-14}$. The relatively young lowland plains and Late Noachian to Early Hesperian faulting along the dichotomy boundary led to models suggesting late-stage formation of the crustal dichotomy ${ }^{5,6}$. Predictions from planetary accretion models and isotope data from the SNC (Shergottites, Nakhlites and Chassigny) meteorites suggest that the crust of Mars formed very early, within $50 \mathrm{Myr}$ of the formation of the Solar System (see ref. 15). This presents a challenge even for models invoking early episodes of plate recycling ${ }^{16}$ and convection driven subcrustal transport ${ }^{17,18}$, because these mechanisms require timescales of the order of hundreds of millions of years to form the dichotomy ${ }^{15}$.

The Mars Orbiter Laser Altimeter (MOLA) on Mars Global Surveyor revealed a population of craters ${ }^{19}$ and subdued quasi-circular depressions (QCDs) ${ }^{9-11}$ in the northern lowlands, interpreted to be ancient impact craters and basins buried by subsequent resurfacing. QCDs are identified as possible impact features on the basis of concentric segments of topographic contours fitted to stretched MOLA data ${ }^{9}$. The areal density of QCDs suggests that the northern lowland crust is comparable in age to the exposed southern highlands, but younger than the highlands basement that includes highland QCDs ${ }^{11}$. To date, there has been no independent confirmation (with the exception of the Utopia basin based on gravity and
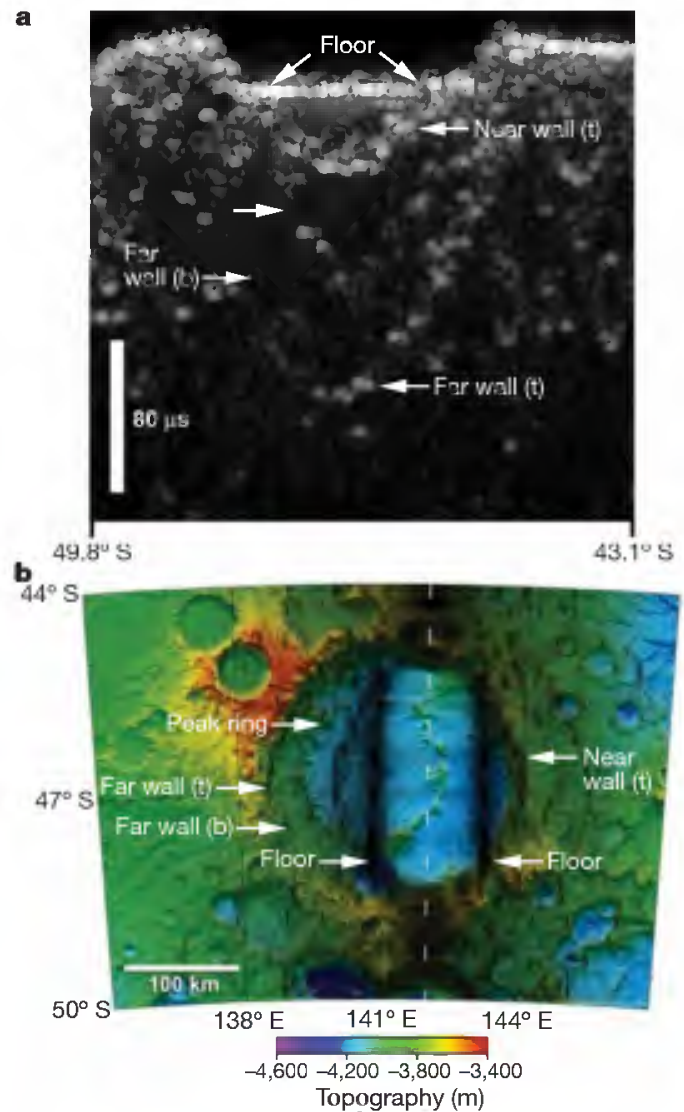

Figure 1 | MARSIS surface clutter simulation of the Kepler basin. a, b, The radargram (a) and the ground-range surface projection overlaid on MOLA topography (b) simulate the MARSIS $4 \mathrm{MHz}$ band. The basin rim walls, both top ( $\mathrm{t}$ ) and bottom (b) from the near and far walls relative to the ground track, the basin floor, and the peak ring are sources of echoes (labelled). The white dashed line indicates the location of simulated nadir ground track.

${ }^{1}$ Center for Earth and Planetary Studies, National Air and Space Museum, Smithsonian Institution, Washington DC 20560, USA. ${ }^{2}$ Center for Remote Sensing of Ice Sheets, The University of Kansas, Lawrence, Kansas 6604S, USA. ${ }^{3}$ Jet Propulsion Laboratory, California Institute of Technology, Pasadena, California 91109 , USA. ${ }^{4}$ Infocom Department, "La Sapienza" University of Rome, 00184 Rome, Italy. ${ }^{5}$ Lunar and Planetary Institute, 3600 Bay Area Boulevard, Houston, Texas 77058, USA. ${ }^{6}$ NASA/Goddard Space Flight Center, Greenbelt, Maryland 20771, USA. ${ }^{7}$ Department of Earth and Planetary Sciences, Washington University, St Louis, Missouri 63130, USA. ${ }^{8}$ Proxemy Research, Laytonsville, Maryland 20882, USA. 
magnetic data ${ }^{20}$ ) that QCDs in the lowlands are related to impact features. MARSIS is providing new data on the shallow crust of Mars ${ }^{8}$. We report here radar echoes obtained by MARSIS in the early phase of operations that indicate buried impact features in the northern lowlands. The MARS1S data collected thus far reveal 11 buried basins, many with no expression in imaging or topography.

The MARSIS instrument is a multi-frequency synthetic aperture orbital sounding radar that operates in four frequency bands between 1.3 MHz and $5.5 \mathrm{MHz}$ in its subsurface sounding modes ${ }^{8}$ (Supplementary Note 1 ). The first months of MARSIS operations (June-July 2005) were over the northern lowlands. Much of the smooth plains of the northern lowlands consist of Late Hesperian and Early Amazonian age sedimentary surficial deposits of the Vastitas Borealis Formation ${ }^{21-23}$. Partially buried by these surficial deposits are numerous wrinkle ridges similar to ridges found in exposed volcanic plains in the highlands ${ }^{19}$. Evidence of olivine-rich deposits associated with some fresh impact craters in the lowlands from the OMEGA (Observatoire pour la Minéralogie, l'Eau, les Glaces, et l'Activité) instrument on the Mars Express spacecraft suggests that the ridged plains beneath the Vastitas Borealis Formation sediments are volcanic in origin ${ }^{24}$.

Time-delay renderings of MARSIS sounding data (radargrams) over the northern lowlands show parabolic-shaped echoes interpreted to be off-nadir clutter from buried features. Simulated radar reflections from the $\sim 230$-km-diameter Kepler impact basin using MOLA topography have the same distinctive parabolic shape (Fig. 1). Kepler exhibits many of the characteristics typical of impact basins of its size. The rim walls in some locations are broad and terraced, and the basin has a peak ring structure that is common in martian craters with diameters $>45 \mathrm{~km}$ (ref. 25). Comparison of the parabolic echoes in the simulation radargram (Fig. Ia) with the echoes projected to ground-range geometry (Fig. 1b) indicates that the sources of the reflections are the top and bottom of the rim walls, the peak ring, and the basin floor. Because MARSIS receives surface and subsurface radar backscatter from the right and left of the ground track simultaneously, there is a left/right ambiguity, and thus echoes are projected on both sides of the track.
Adjacent orbits 1892 and 1903 over Chryse Planitia show multiple, complex parabolic echoes (Fig. 2a, b), analogous to the Kepler basin simulated echoes (Fig. 1). In ground-range projections of the radargrams, parabolic echoes project into arcs with constant curvature on the surface that can be used to infer the probable location and size of the basin (Fig. 2c, d). Overlapping echoes in the ground-range projections of the two radargrams indicate that returns are from the same subsurface feature, eliminating the left/right ambiguity. Circular fits to projected arcs suggest that an $\sim 220$-km-diameter basin is superimposed on a larger $\sim 310-\mathrm{km}$-diameter basin (Supplementary Note 2). A prominent linear echo in orbit 1903 (Fig. 2a, c) is comparable to the simulated echo generated by the floor of Kepler basin (Fig. 1). The time delay corresponds to a depth of $2.0-2.5 \mathrm{~km}$ if the feature is directly below the spacecraft, and it may be the interface between the basin floor and the fill material ${ }^{8}$. Parabolic echoes in MARSIS orbits over Amazonis Planitia suggest buried basins beneath relatively young (Middle to Late Amazonian) lava flows. Ground-range projection of echoes shows that, as with orbits 1892 and 1903 (Fig. 2), arcs may consist of distinct segments with different radii of curvature. A parabolic echo in orbit 1886 (Fig. 3a) suggests an $\sim 210-\mathrm{km}$-diameter basin that the orbit track crosses near the basin centre. A second discontinuous echo may be from a rim related structure, suggesting that the basin could be up to $\sim 240 \mathrm{~km}$ in diameter. The ground-range projection of a prominent parabolic echo in orbit 1897 (Fig. 3b) is consistent with a buried basin $\sim 140 \mathrm{~km}$ in diameter (Fig. 3d). Overall, buried basins have been detected in Chryse, Acidalia, Amazonis, Elyisium and Utopia Planitiae (Table 1) (Supplementary Note 3 ).

The buried basins detected by MARS1S can be used to estimate an independent areal crater density $(N(200)$ : a measure of the cumulative number of basins with diameters $>200 \mathrm{~km}$ per $10^{6} \mathrm{~km}^{2}$ ) for the lowland crust. The area of the northern lowlands surveyed by MARS1S is estimated to be $\sim(4.63 \pm 1) \times 10^{6} \mathrm{~km}^{2}(\sim 14 \pm 3 \%$ of the lowlands) (Supplementary Note 4). This corresponds to an $N(200)$ crater density for the lowland crust of $\sim 1.9$ (range $\sim 1.6-$ 2.6), greater than the $N(200)$ crater density of Early Noachian boundary $\left(1.28\right.$, based on $N(16)$ crater counts ${ }^{26}$ extrapolated to larger
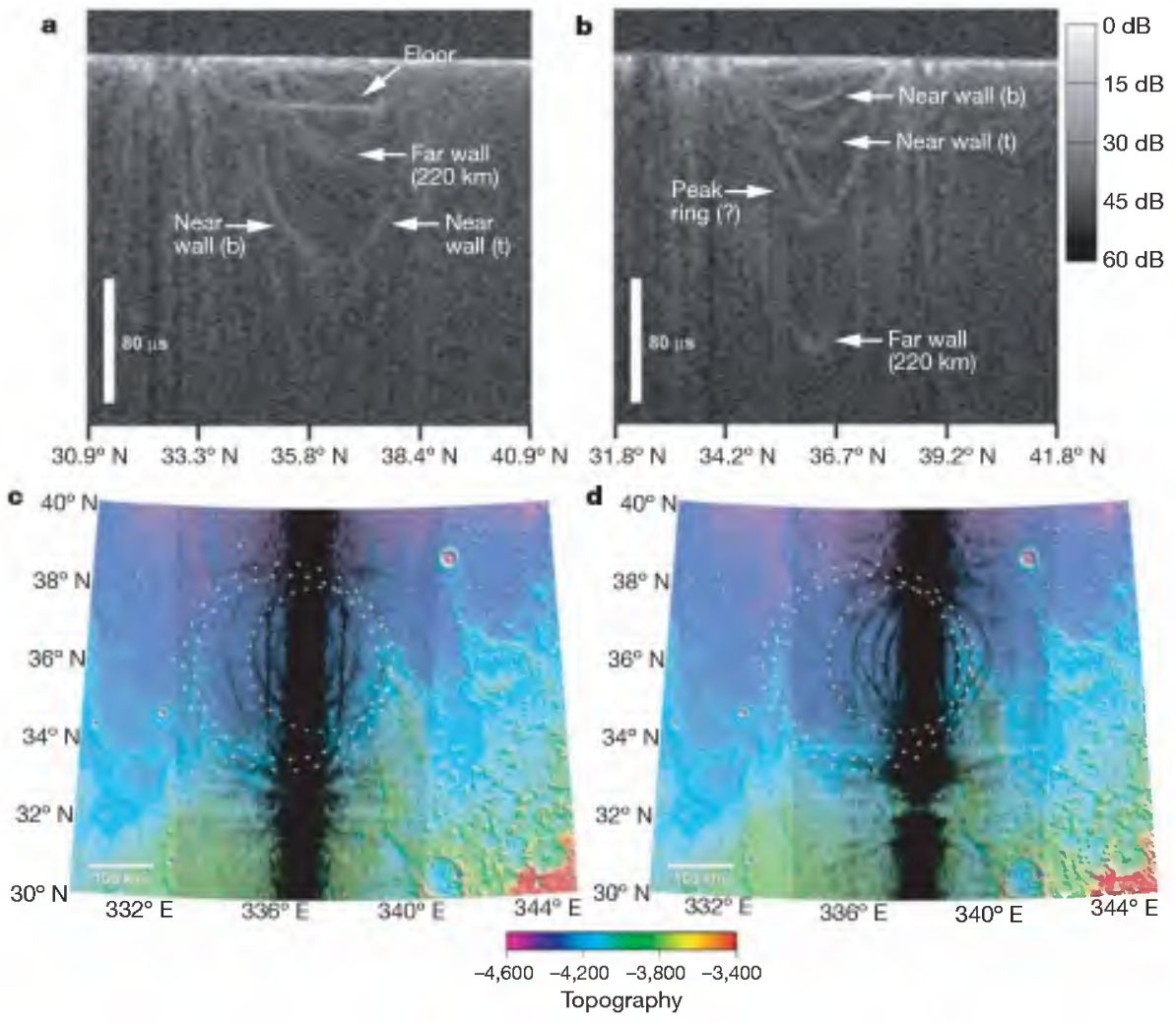

b

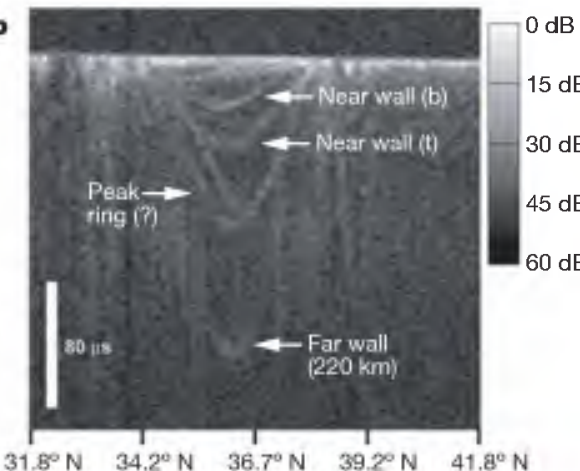

d
Figure 2 | Radargrams and ground-range projections of MARSIS data in Chryse Planitia. a, b, Radargrams for MARSIS orbits 1903 (a) and 1892 (b) that cross Chryse Planitia. Echoes are plotted in time-delay versus position along the orbit track. The peak surface return is corrected to agree with the MOLA topography. c, d, Ground-range projections of orbit 1903 (c) and 1892 (d) radargrams are overlaid on MOLA colour-coded shaded relief. Parabolic echoes that project as arcs on the surface are interpreted to be from the near and far rim walls (relative to the orbit track) of buried impact basins. The dashed white circles are approximate fits to the arcs (echoes labelled in radargrams). Echoes are interpreted to be from the far rim wall of an $\sim 220-\mathrm{km}$-diameter basin (corresponding echoes in $\mathbf{a}$ and $\mathbf{b}$ labelled 'Far wall') superimposed on a larger $\sim 310-\mathrm{km}$-diameter basin that may have echoes from the top and bottom of the near rim wall (corresponding echoes in $\mathbf{a}$ and $\mathbf{b}$ labelled 'Near wall'). 
diameters with a -2 power law). An Early Noachian age for the northern lowland crust is also suggested by a cumulative frequency plot of the MARSIS basins (Supplementary Fig. 1).

The MARSIS-based estimate of the crater density age of the lowlands crust is a lower limit because of the probability that not all the buried basins in the area surveyed have been detected. Several factors may contribute to the lack of subsurface scatter from buried impact basins, in particular the dielectric properties of the fill materials. The likelihood of detection is enhanced if basins are filled with materials that have a significant dielectric contrast with the crustal material. Conversely, basins filled with materials that are similar to the crustal material and homogenously stratified may not be detected because the dielectric contrast is too small. Simulations indicate that the rim wall echo is sensitive to the rim wall slope. This suggests that there may be viewing geometry limitations and that only some combination of rim wall slope and spacecraft altitude results in a surface perpendicular to the instrument viewing angle. Other factors, like the degradation state and depth of burial, may also influence the detection of subsurface echoes from buried impact basins.

The QCDs in the northern lowlands with diameters $>200 \mathrm{~km}$ give an $N(200)$ crater density of 2.5 (ref. 11), comparable to the MARSISbased $N(200)$ crater density for the lowland crust. Many of the mapped QCDs ${ }^{11}$ are within the area of the northern lowlands surveyed by MARSIS (Fig. 4). Some of these QCDs coincide with MARSIS basins. The location of a 315-km-diameter QCD $\left(\sim 35^{\circ} \mathrm{N}\right.$, $336^{\circ} \mathrm{E}$ ) roughly corresponds to the 3I0-km-diameter MARSIS basin in Chryse Planitia. A 470-km-diameter MARSIS basin in Acidilia Planitia approximately matches the location of an $\sim 460-\mathrm{km}$-diameter QCD $\left(\sim 49^{\circ} \mathrm{N}, 34 \mathrm{I}^{\circ} \mathrm{E}\right.$ ) (Fig. 4). Another QCD $\sim 440 \mathrm{~km}$ in diameter $\left(\sim 56^{\circ} \mathrm{N}, 14^{\circ} \mathrm{E}\right)$ corresponds approximately to the $470-\mathrm{km}-$ diameter MARSIS basin in eastern Acidilia (Fig. 4). In Elyisum Planitia, the location of the $200-\mathrm{km}$-diameter MARSIS basin
Table 1 | MARSIS buried basins in the northern lowlands

\begin{tabular}{lcccc}
\hline Location & $\begin{array}{c}\text { Lat., Long. } \\
\left({ }^{\circ} \mathrm{N}, \mathrm{E}\right)\end{array}$ & $\begin{array}{c}\text { Diameter } \\
(\mathrm{km})\end{array}$ & Orbits & Bands (MHz) \\
\hline Chryse & 36,337 & $290-310$ & 1903,1892 & 3,4 \\
Chryse & 36,336 & 220 & 1903,1892 & 3,4 \\
Acidalia & 48,342 & $400-470$ & 1881 & 3 \\
Acidalia & $53,339^{*}$ & 220 & 1881 & 3 \\
Acidalia & 50,338 & 150 & 1903 & 3 \\
Acidalia & $54,15^{\star}$ & 470 & 1899 & 3 \\
Amazonis & 19,208 & $210-240$ & 1886 & 4 \\
Amazonis & $33,206^{*}$ & 140 & 1897 & 4 \\
Amazonis & $13,208^{*}$ & 210 & 1875 & 4 \\
Elysium & $6,144^{*}$ & $120-200$ & 1872 & 4 \\
Utopia & $16,112^{*}$ & 270 & 1887 & 3
\end{tabular}

The MARSIS subsurface sounding bands are centred at $1.8,3.0,4.0$ and $5.0 \mathrm{MHz}$.

* Basin centre location is not uniquely determined.

approximately coincides with a $220-\mathrm{km}$-diameter $\mathrm{QCD}\left(\sim 6^{\circ} \mathrm{N}\right.$, $\mathrm{I} 45^{\circ} \mathrm{E}$ ) (Fig. 4). After minimizing the offset by allowing for the left/right ambiguity in the basin location, the offset between the centres of the MARSIS basins and the QCDs ranges from $\sim 60 \mathrm{~km}$ to $>120 \mathrm{~km}$. Most of the buried basins detected by MARSIS have no discernable topographic expression in MOLA-based shaded relief maps (Fig. 3, Supplementary Note 3). The agreement between QCDs and the MARSIS basins detected thus far supports the interpretation that QCDs are the surface expression of buried basins. However, the small number of QCDs that correlate with detected subsurface echoes may indicate that not all QCDs are related to buried basins.

The age of the northern lowland crust is critical in determining when the hemispheric dichotomy formed, and in constraining models for its origin. The results of this study indicate that the northern lowland crust is ancient, in agreement with the QCD-based crater density age ${ }^{9-11}$, and suggest that the dichotomy formed in the Early
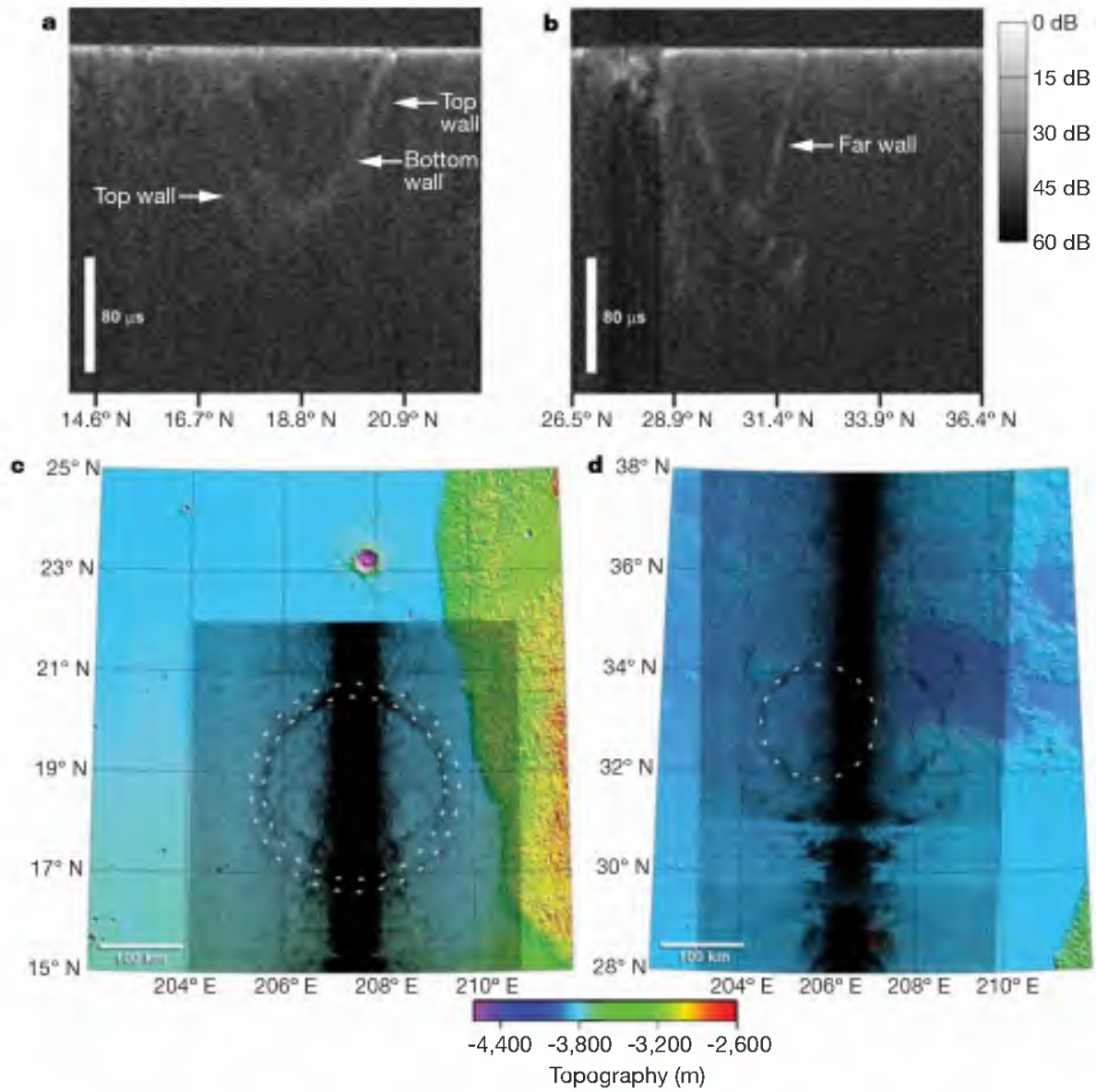

Figure 3 | Radargrams and ground-range projections of MARSIS data in Amazonis Planitia. a, b, Radargrams showing MARSIS data for orbits 1886 (a) and 1897 (b) that cross Amazonis Planitia. c, d, Ground-range projections of radargrams for 1886 (c) and 1897 (d) are overlaid on MOLA colour-coded shaded relief. The dashed white circles are approximate fits to the arcs (echoes labelled in radargrams). Echoes in 1886 (c) are interpreted to be from the top and bottom rim wall of an $\sim 210-\mathrm{km}$ diameter basin (corresponding echoes labelled in a). The echo in 1897 (d) is interpreted to be from the far rim wall of an $\sim 140$-km-diameter basin (corresponding echo labelled in $\mathbf{b}$ ). The best fit to the echo indicates that the orbit track is offset from the basin centre, thus the left/right ambiguity in the data does not allow a unique determination of the basin centre. 


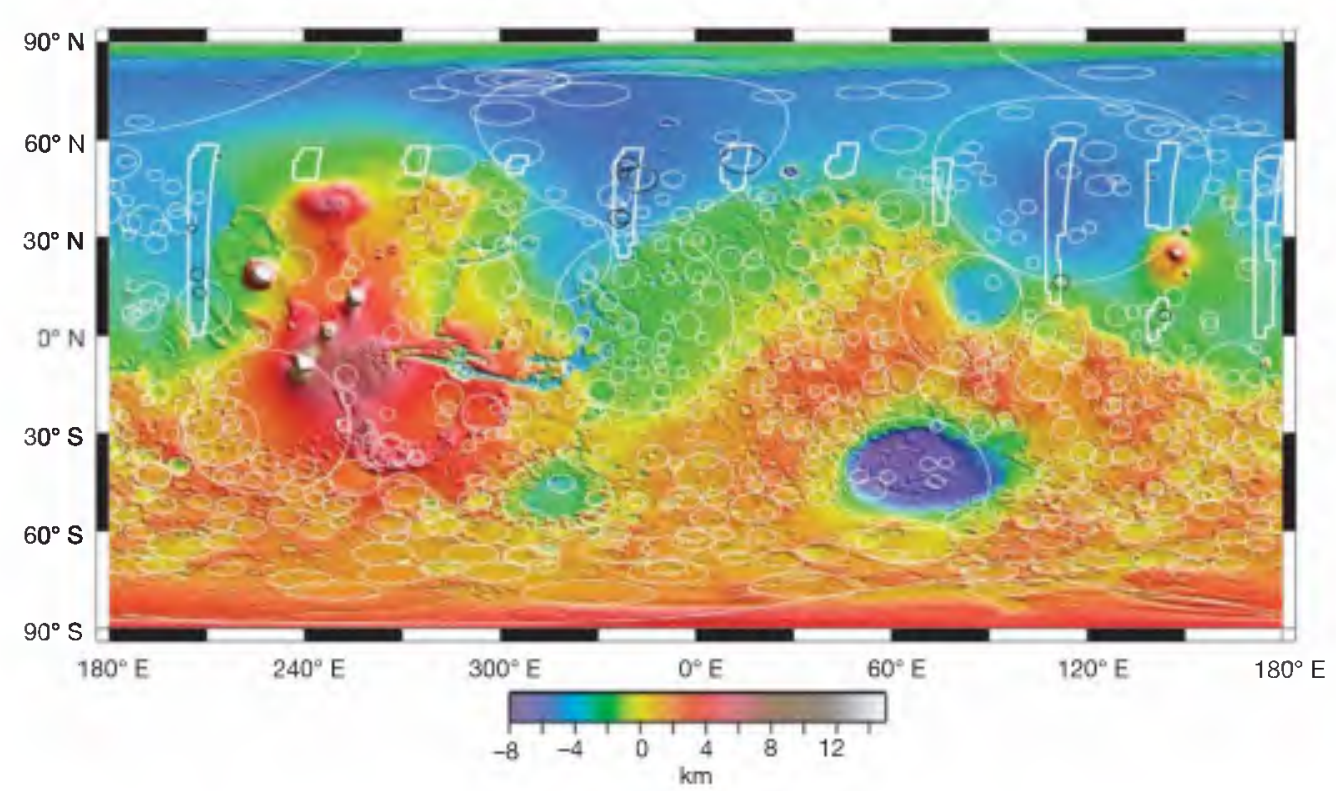

Figure 4 Locations of MARSIS buried basins. The locations and inferred diameters from MARSIS echoes are shown in black on MOLA colour-coded shaded relief. The locations and diameters of QCDs with diameters $>200 \mathrm{~km}$ mapped in ref. 11 are plotted in white. White polygons show the area covered by MARSIS orbits (see text). Where there is left/right ambiguity in the location of a MARSIS basin that coincides with a QCD, the plotted location reflects the minimum offset between the centres of the MARSIS basin and the QCD.

Noachian. The question of how early the hemispheric dichotomy formed may be addressed if the difference in age between the highland and lowland crust can be determined. The QCD-based N(200) crater density for the highlands is estimated to be $\sim 4.5$ (exposed basins and QCDs) with an upper limit of $\sim 8.5$ based on extrapolation of the largest highland basins (exposed basins and QCDs) ${ }^{11}$. The larger QCD-based $N(200)$ crater density suggests that the highland crust is older than the lowland basement. This areal crater density, however, includes many suspected impact basins that can not be independently verified by MARSIS sounding data or other geophysical data. Another approach to evaluating the age difference between the highland and lowland crust is by comparing the MARSIS-based crater density for the lowland basement to the crater density of the exposed highland basement. One of the oldest and best preserved areas of highland basement, in the area of Claritas Fossae $\left(\sim 28^{\circ} \mathrm{S}, 259^{\circ} \mathrm{E}\right)$, has an $N(16)$ crater density of $294 \pm 8 \mathrm{I}$ (ref. 26$)$. This corresponds to an $N(200)$ density of $\sim 1.9 \pm 0.5$ (based on extrapolation to larger diameters using a -2 power law), comparable to the MARSIS-based $N(200)$ crater density of the lowland basement. Thus, we conclude from the MARSIS data that the lowland crust is at least as old as the oldest exposed highland crust. Although the MARSIS-based $N(200)$ crater density for the lowlands and the extrapolated $N(200)$ density for the highlands are lower limits, the similarity in age suggests that the crustal dichotomy formed early in the geologic evolution of Mars.

\section{Received 9 June; accepted 12 October 2006.}

1. Wilhelms, D. E. \& Squyres, S. W. The martian hemispheric dichotomy may be due to a giant impact. Nature 309, 138-140 (1984)

2. McGill, G. E. Buried topography of Utopia, Mars: Persistence of a giant impact depression. J. Geophys. Res. 94, 2753-2759 (1989).

3. Frey, H. \& Schultz, R. A. Large impact basins and the mega-impact origin for the crustal dichotomy on Mars. Geophys. Res. Lett. 15, 229-232 (1988).

4. Wise, D. U Golombek, M. P. \& McGill, G. E. Tharsis province of Mars: Geologic sequence, geometry and a deformation mechanism. Icarus 38, 456-472 (1979).

5. McGill, G. E. \& Dimitriou, A. M. Origin of the martian global dichotomy by crustal thinning in the late Noachian or early Hesperian. J. Geophys. Res. 95, 12595-1260S (1990)

6. Sleep, N. H. Martian plate tectonics. J. Geophys. Res. 99, 5639-5656 (1994).

7. Elkins-Tanton, L. T., Parmentier, E.M. \& Hess, P. C. The formation of ancient crust on Mars through magma ocean processes. J. Geophys. Res. 110, E12S01, doi:10.1029/2005JE002480 (2005).

8. Picardi, G. et al. Radar soundings of the subsurface of Mars. Science 310 , 1925-1928 (200S).

9. Frey, H. V., Roark, J. H., Shockey, K. M., Frey, E. L. \& Sakimoto, S. E. H. Ancient lowlands on Mars. Geophys. Res Lett 29, doi:101029/2001GL 013832 (2002).

10. Frey, H. V. Impact constraints on the age of origin of the lowlands of Mars. Geophys. Res. Lett. 33, doi:10.1029/2005GL024484 (2006).
11. Frey, H. V. Impact constraints on, and a chronology for, major events in early Mars history. J. Geaphys. Res. 111, doi:10.1029/200SJE002449 (2006).

12. Scott, D. H. \& Tanaka, K. L. Geologic map of the western equatorial region of Mars, scale 1:15,000,000. US Geol. Surv. Misc. Invest. Ser. Map I-1802-A, (1986)

13. Greeley, R. \& Guest, J. E. Geologic map of the eastern equatorial region of Mars, scale 1:1S,000,000. US Geol. Surv. Misc. Invest. Ser. Map I-1802-B, (1987).

14. Tanaka, K. L. \& Scott, D. H. Geologic maps of the polar regions of Mars, scale 1:15,000,000. US Geol. Surv. Misc. Invest. Ser. Map I-1802-C, (1987)

1S. Solomon, S. C. et al. New perspectives on ancient Mars. Science 307, 1214-1220 (2005).

16. Lenardic, A., Nimmo, F. \& Moresi, L. Growth of the hemispheric dichotomy and the cessation of plate tectonics on Mars. J. Geophys. Res. 109, E02003, doi:10.1029/2003JE002172 (2004)

17. Zhong, S. \& Zuber, M. T. Degree-1 mantle convection and the crustal dichotomy on Mars. Earth Planet. Sci. Lett. 189, 75-84 (2001)

18. Roberts, J. H. \& Zhong, S. Degree-1 convection in the Martian mantle and the origin of the hemispheric dichotomy. J. Geophys. Res. 111, doi:10.1029/2005JE002668 (2006).

19. Head, J. W., Kreslavsky, M. A. \& Pratt, S. Northern lowlands of Mars: Evidence for widespread volcanic flooding and tectonic deformation in the Hesperian Period. J. Geophys. Res. 107, doi:10.1029/2000JE00144S (2002).

20. Zuber, M. T. The crust and mantle of Mars. Nature 412, 220-227 (2001).

21. Tanaka, K. L. et al. Resurfacing history of the northern plains of Mars based on geologic mapping of Mars Global Surveyor data. J. Geophys. Res. 108 (E4), doi:10.1029/2002JE001908 (2003).

22. Tanaka, K. L. et al. Geologic map of the northern plains of Mars. US Geol. Surv. Misc. invest. Ser. Map I-2888, (2005)

23. Kreslavsky M. A \& Head, J.W. The fate of outflow channel effluents in the northern lowlands of Mars: The Vastitas Borealis Formation as a sublimation residue from frozen ponded bodies of water. J. Geophys. Res. 107 (E12), 5121, doi:10.1029/2001JE001831 (2002).

24. Mustard, J. F. et al. Olivine and pyroxene diversity in the crust of Mars. Science 307, 1594-1597 (2005).

25. Melosh, H. J. Impact Cratering: A Geologic Process (Oxford Univ. Press, New York, 1989).

26. Tanaka, K. L. The stratigraphy of Mars. J. Geophys. Res. 91, E139-E158 (1986).

Supplementary Information is linked to the online version of the paper at www.nature.com/nature.

Acknowledgements We thank J. W. Head and D. D. Blankenship for constructive criticism and advice that greatly improved the paper. We also thank H. V. Frey for providing the locations and diameters of the QCDs. We are grateful to the other members of the MARSIS Science team and to the instrument operation staff. MARSIS is managed by the Agenzia Spaziale Italiana (ASI) and the National Aeronautics and Space Administration (NASA). The Mars Express mission is managed and operated by the European Space Agency. The research activities of the MARSIS PI and Italian investigators were supported by the Mars Express/AS programme; the work of the US investigators was supported by the Mars Express/ NASA project.

Author Information Reprints and permissions information is available at www.nature.com/reprints. The authors declare no competing financial interests. Correspondence and requests for materials should be addressed to T.R.W. (watterst@si.edu). 


\section{TABLE OF CONTENTS}

MARSIS Radar Sounder Evidence of Buried Basins in the Northern Lowlands of Mars

Thomas R. Watters, Carl J. Leuschen, Jeffrey J. Plaut, Giovanni Picardi, Ali Safaeinili, Stephen M. Clifford, William M. Farrell, Anton B. Ivanov, Roger J. Phillips, Ellen R. Stofan and the MARSIS Science Team

SUPPLEMENTARY NOTES

S1. MARSIS ANTENNA AND INSTRUMENT OPERATIONS

S2. BURIED BASINS IN CHYRSE PLANITIA

S3. BURIED BASINS IN ACIDILIA, AMAZONIA, ELYISUM, AND UTOPIA PLANITIEA

Supplemental Note Figure 1

Supplemental Note Figure 2

Supplemental Note Figure 3

Supplemental Note Figure 4

Supplemental Note Figure 5

Supplemental Note Figure 6

S4. ESTIMATE OF MARSIS COVERAGE OF THE NORTHERN LOWLANDS

SUPPLEMENTARY FIGURE AND LEGEND

FIGURE S1.

REFERENCES 


\section{SUPPLEMENTARY NOTES}

\section{S1. MARSIS ANTENNA AND INSTRUMENT OPERATIONS}

The MARSIS antenna is $40 \mathrm{~m}$ in length and radiates with a peak transmitted power of $\sim 10$ Watts $^{1}$. The instrument has $1 \mathrm{MHz}$ instantaneous bandwidth that provides a free-space range resolution of approximately $150 \mathrm{~m}$. The typical spatial resolution is 10 to $30 \mathrm{~km}$ crosstrack and 5 to $10 \mathrm{~km}$ along-track. The signal-to-noise ratio after summing, usually of 60-300 pulses at a pulse repetition frequency of $127 \mathrm{~Hz}$, is $\sim 30$ to $50 \mathrm{~dB}$. Subsurface sounding data are generally obtained when the spacecraft altitude is between 250 to $800 \mathrm{~km}$.

MARSIS subsurface sounding data are greatly influenced by the ionosphere of Mars ${ }^{2,3}$. Radar pulses can not reach the surface if the ionospheric plasma frequency is close to or above the sounding frequency. To avoid interference from the ionosphere, the instrument is generally operated when the spacecraft pericenter is on the nightside of Mars. Data are collected in the subsurface-3 mode which performs pre-summing onboard and returns complex spectra from three synthetic aperture (Doppler) channels for each of two frequency bands. Ground processing involves transforming the spectra into the time domain and correcting for phase distortion in the ionosphere $^{3}$. Because of the high variability in the ionospheric phase distortion ${ }^{3}$, the time delay of the initial surface return is corrected to agree with the MOLA topography along the orbit track. This allows direct comparison with MOLA derived surface clutter models, which aids in separating surface returns from subsurface returns.

\section{S2. BURIED BASINS IN CHYRSE PLANITIA}

Fits to echoes in the ground-range projections suggest three possibilities; the echoes can be accounted for by a single $\sim 220 \mathrm{~km}$-diameter basin, a larger $\sim 310 \mathrm{~km}$-diameter basin, or two superimposed basins. A single $\sim 220 \mathrm{~km}$-diameter basin can encompass most of the overlapping parabolic echoes (Supplemental Note Fig. 1). Two parallel, overlapping sets of arcs separated by $\sim 20 \mathrm{~km}$ are interpreted to be top and bottom near rim wall reflections of a buried basin $\sim 290$ to $310 \mathrm{~km}$ in diameter (Supplemental Note Fig. 1). Other interior echoes may be from rim wall slumps or a discontinuous peak ring structure. However, many of the echoes in the 1892 and 1903 radargrams appear to extend to the surface (intersecting with the surface return), inconsistent with a source for the echoes at or near the floor of the basin as would be expected for rim wall slumps or a peak ring. MOLA-based surface clutter models for orbits 1892 and 1903 show that the echoes can not be accounted for by topography. 


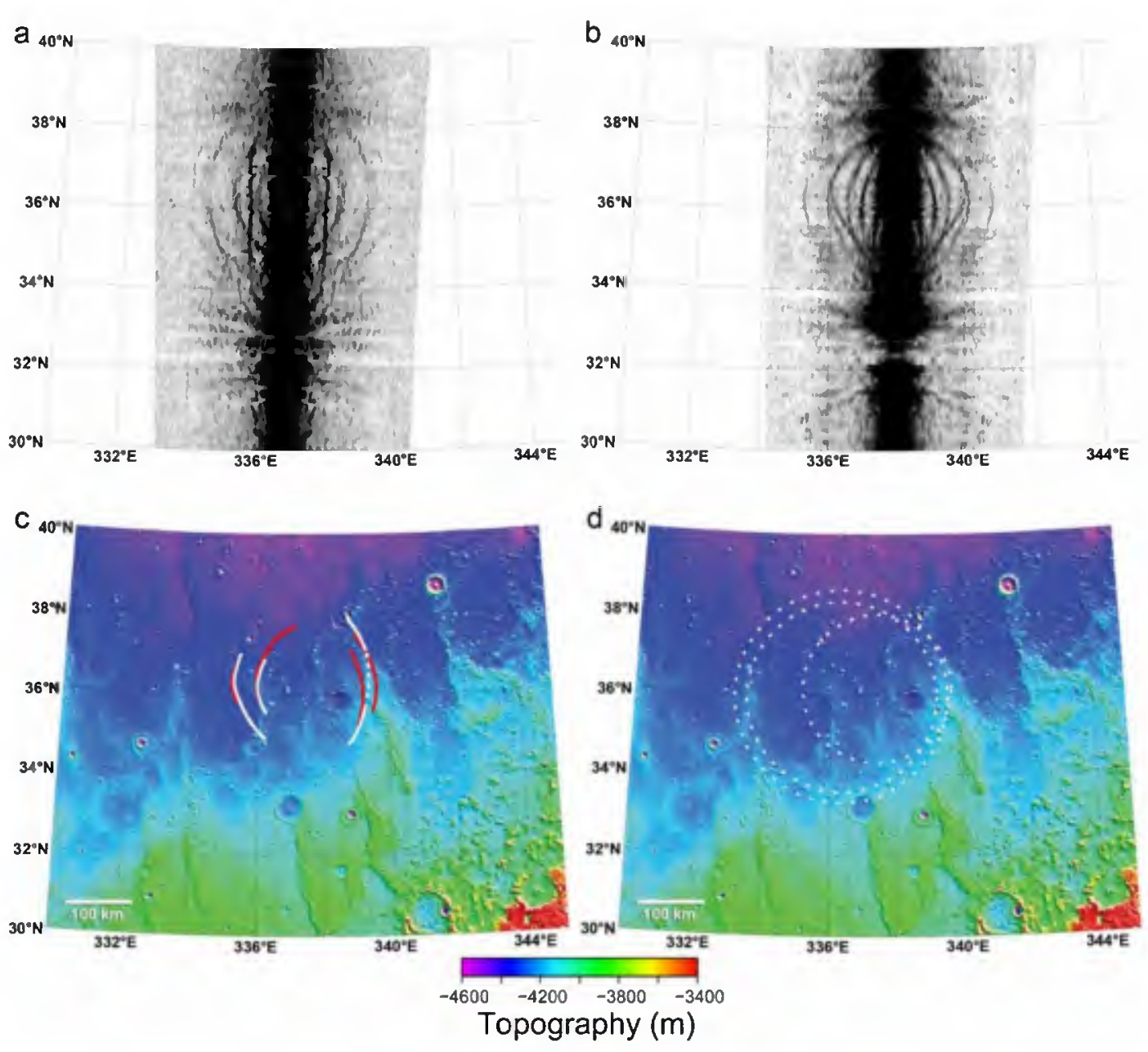

Supplemental Note Fig. 1. Ground-range projections of radargrams for 1903 (a) and 1892 (b). The locations of overlapping echoes (c) and the inferred buried basins (d) are shown on MOLA color coded shaded relief maps. Overlapping echoes (c) in the ground-range projection of 1903 (white) and 1892 (red) radargrams indicate returns from the same subsurface reflectors. Fits to the projected arcs indicated by dashed white circles (d) show the approximate locations of two buried impact basins, an $220 \mathrm{~km}$-diameter basin and an $\sim 310 \mathrm{~km}$-diameter basin. Other echoes may be attributed to a possible peak ring structure. 


\section{S3. BURIED BASINS IN ACIDILIA, AMAZONIA, ELYISUM, AND UTOPIA PLANITIEA}

Parabolic echoes in MARSIS data often consist of a single echo or pairs of echoes that can be either continuous or discontinuous. A broad, diffuse parabolic echo in orbit 1881 indicates buried basin in Acidilia Planitia 400 to $470 \mathrm{~km}$ in diameter (Supplemental Note Fig. 2). The MARSIS echoes are assumed to originate from buried (near-surface) structures, because there is no indication of a broad, parabolic echo in the MOLA-based clutter model for orbit 1881. The basin corresponds to a roughly circular topographic depression. The westernmost extent of the topographic depression is marked by mesas of the Acidalia Mensa (see 4). Two smaller basins, one $\sim 150 \mathrm{~km}$ in diameter and the other $220 \mathrm{~km}$ in diameter are suggested by single, discontinuous parabolic echoes in MARSIS orbits 1881 and 1903 (Supplemental Note Fig. 2). Circular fits to the echo in 1881 suggests that the orbit track does not cross the basin center. The left/right ambiguity in the MARSIS data thus does not allow a unique determination of the location of the center of the basin. However, fits to the echo in 1903 suggest the orbit does cross near the center of the $150 \mathrm{~km}$-diameter basin. Both basins appear to be superposed on the northwestern rim of the $470 \mathrm{~km}$-diameter basin. 


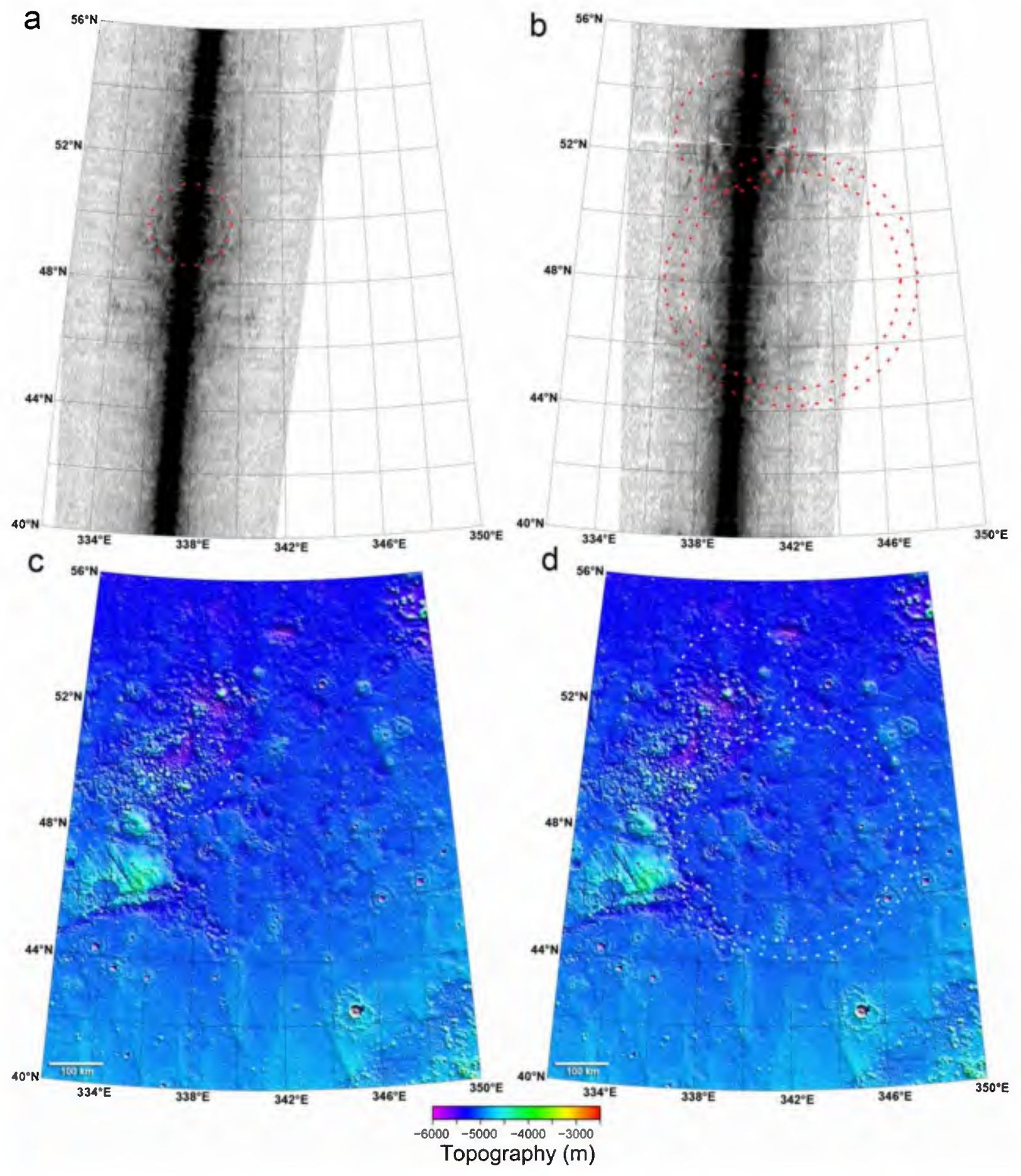

Supplemental Note Fig. 2. Ground-range projections of radargrams for 1903 (a) and 1881 (b). The locations of inferred buried basins (red dashed circles in $2 \mathrm{a}, \mathrm{b}$ and white dashed circles $2 \mathrm{c}$, d) are shown on the ground-range projections and on MOLA color coded shaded relief maps of part of western Acidalia Planitia. 
Evidence of a second large basin in eastern Acidalia Planitia is found in MARSIS orbit 1899. A single, generally continuous parabolic echo in 1899 suggests another $\sim 470 \mathrm{~km}$-diameter basin (Supplemental Note Fig. 3). There is no perceptible expression of this basin in the MOLA shaded relief.
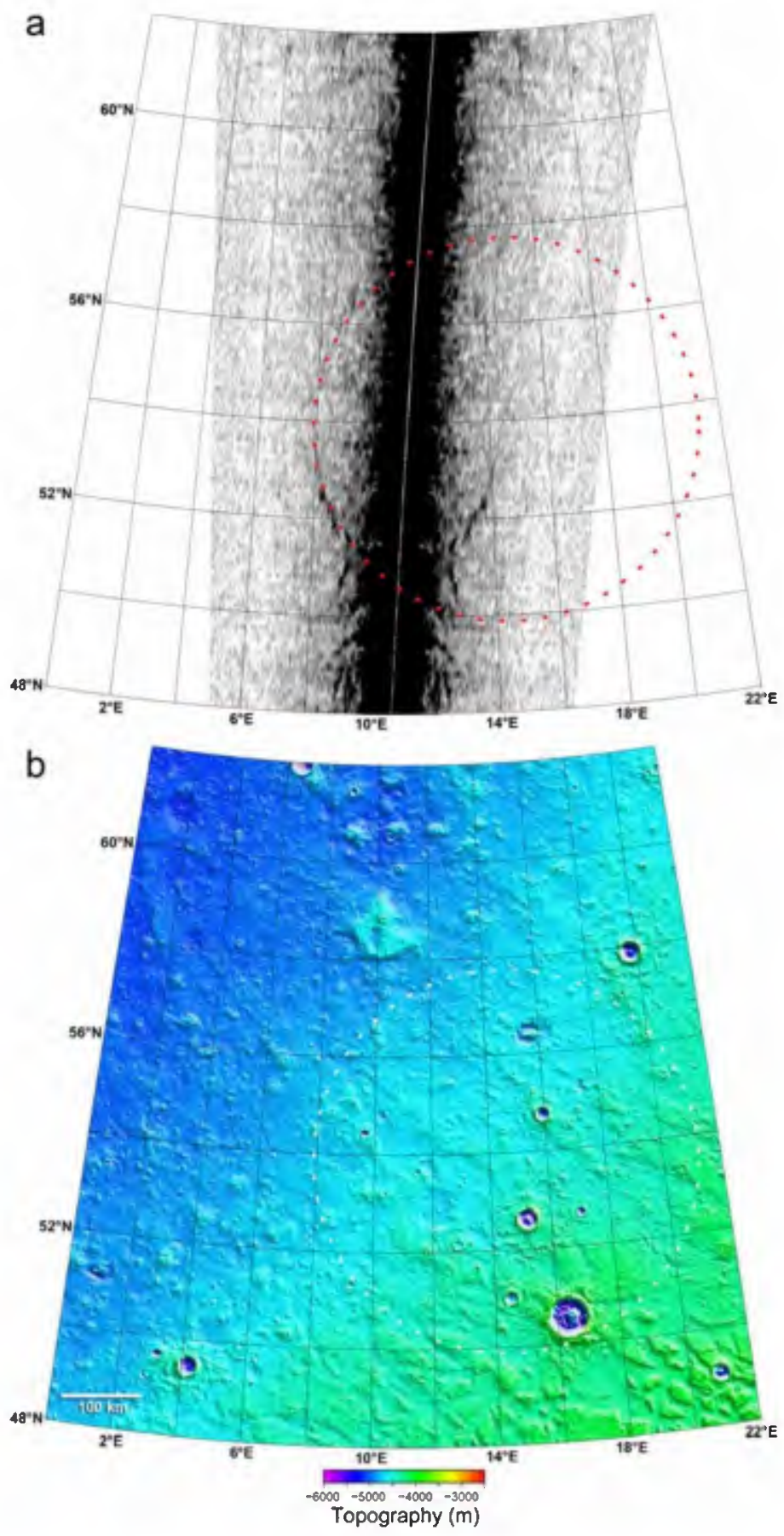

Supplemental Note Fig. 3. Ground-range projection of the radargram for 1899 (a) with the location of an inferred buried basin shown on MOLA color coded shaded relief part of eastern Acidalia Planitia (b). The location of the inferred buried basin is shown by the red dashed circle in $3 \mathrm{a}$ and the white dashed circle $3 \mathrm{~b}$. 
A third basin in southern Amazonis Planitia is suggested by a discontinuous parabolic echo in orbit 1875 (Supplemental Note Fig. 4). The best fit to the echo indicates an $\sim 210 \mathrm{~km}$ diameter buried basin with the orbit track offset from the basin center. The left/right ambiguity in the data does not allow a unique determination of the basin center.
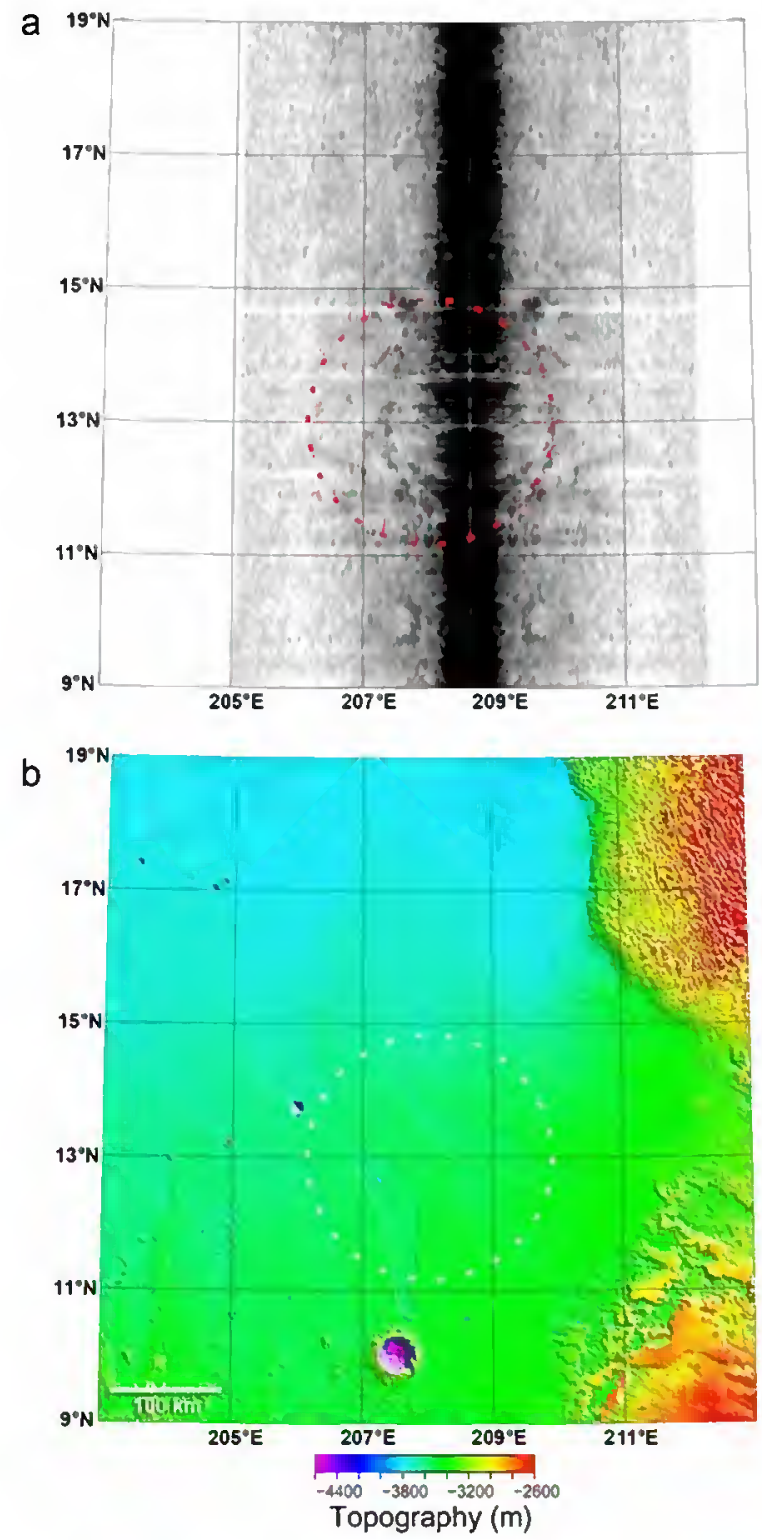

Supplemental Note Fig. 4. Ground-range projection of radargrams for 1875 (a) with the location of an inferred buried basin on MOLA color coded shaded relief of part of southern Amazonis Planitia (b). The location of the inferred buried basin is shown by the red dashed circle in $4 \mathrm{a}$ and the white dashed circle $4 b$. 
MARSIS sounding data over the volcanic plains of Elyisum Planitia indicate a buried basin under a sequence of Late Hesperian to Late Amazonian lava flows. The ground-range projection of a pair of discontinuous parabolic echoes in orbit 1872 suggests a basin with an outer diameter of $\sim 200 \mathrm{~km}$ and an inner diameter of $\sim 120 \mathrm{~km}$ (Supplemental Note Fig. 5). The difference in diameters is too large to be accounted for by reflections from an upper and lower rim wall and the interior echo does not intersect the surface return. This suggests the source of the interior echo may be from a peak ring structure.
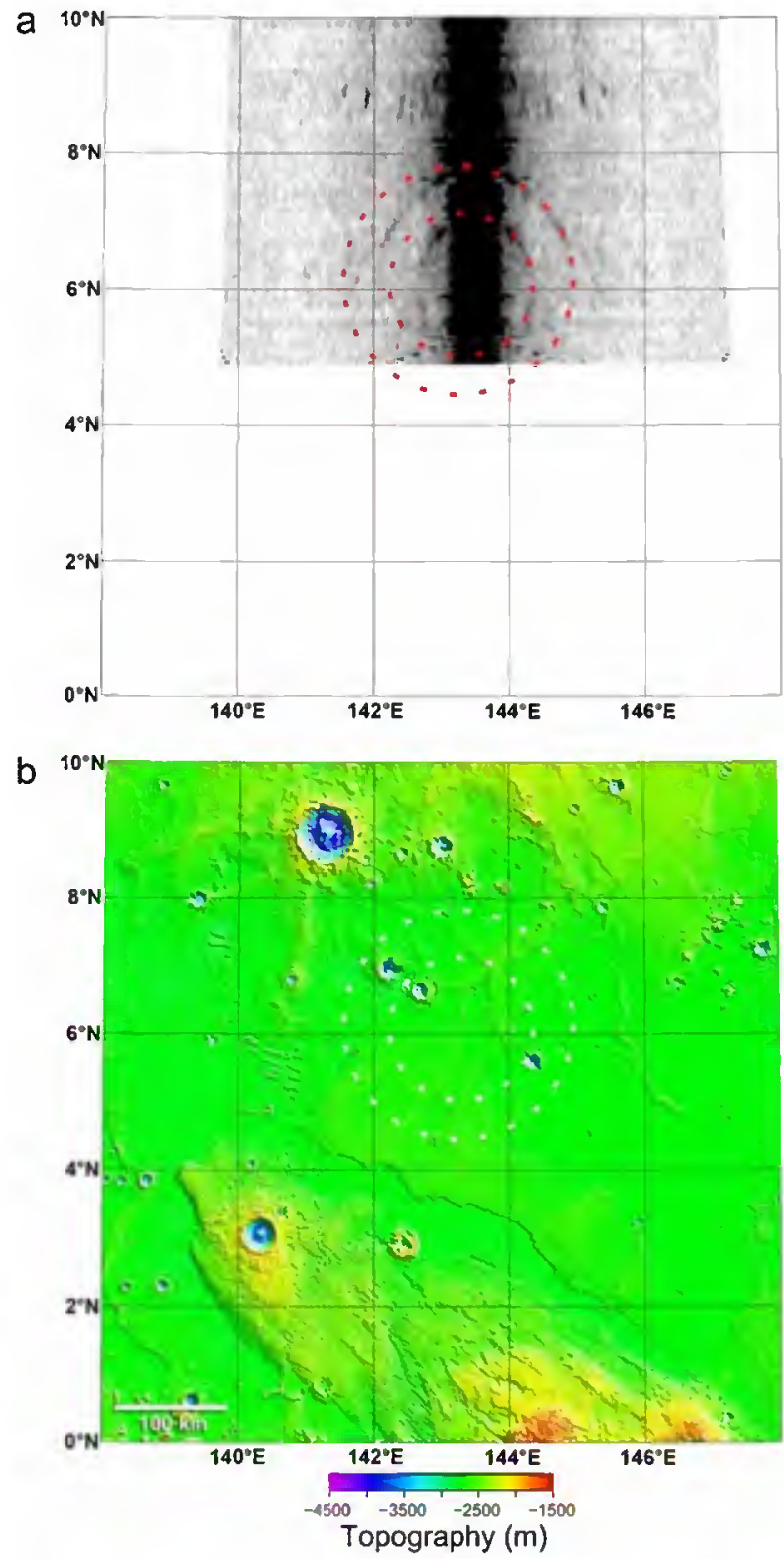

Supplemental Note Fig. 5. Ground-range projection of radargrams for 1872 (a) with the location of an inferred buried basin on MOLA color coded shaded relief of part of southern Elysium Planitia (b). The locations of the inferred buried basin rim wall and a possible peak ring structure are shown by the red dashed circle in $5 \mathrm{a}$ and the white dashed circle $5 \mathrm{~b}$. 
The concavity of the parabolic echoes in radargrams described above is concave up, indicating that the MARSIS orbits passed over the interiors of the buried basins. If the MARSIS orbit passes outside a basin, the exterior rim wall echo is expected to have the opposite concavity; concave down. Such an echo is observed in the sounding data over the lowlands of southern Utopia Planitia (Supplementary Note Fig. 6), just north of the dichotomy boundary in Amenthes. The echo in orbit 1887 suggests a $270 \mathrm{~km}$-diameter basin buried in part beneath the knobby and fretted terrain of Nepenthes Mensae.
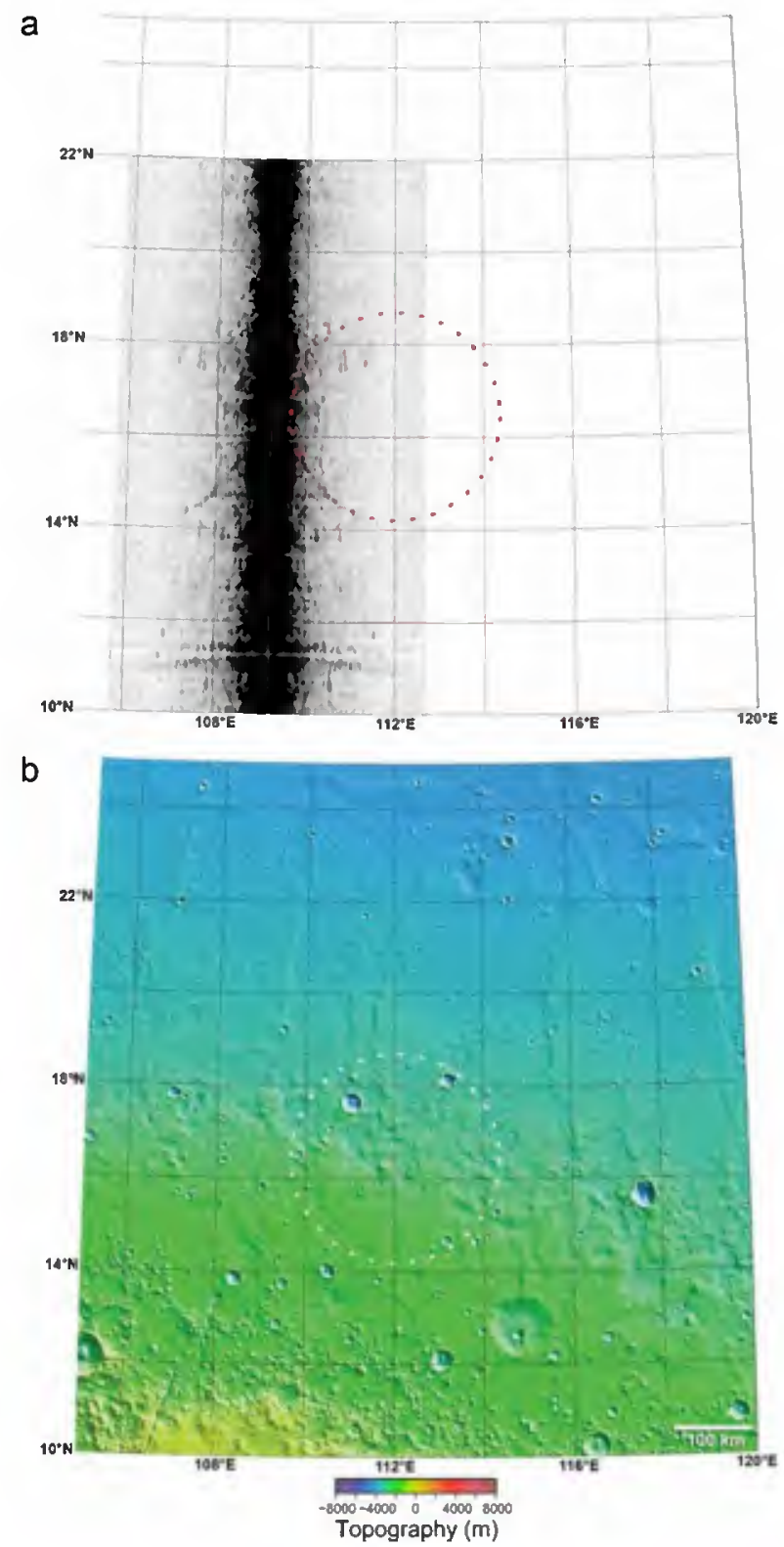

Supplemental Note Fig. 6. Ground-range projection of radargrams for 1887 (a) with the location of an inferred buried basin on MOLA color coded shaded relief of part of southern Utopia Planitia (b). The location of the inferred buried basin is shown by the red dashed circle in 6a and the white dashed circle $6 \mathrm{~b}$. 


\section{S4. ESTIMATE OF MARSIS COVERAGE OF THE NORTHERN LOWLANDS}

During the initial phase of MARSIS operations, 34 orbits with sufficient signal-to-noise crossed the northern lowlands. The area of the lowlands surveyed by MARSIS is strongly dependent on the cross orbit track distance beyond which basins are not likely to be detected. The maximum distance from the basin rims to the orbit tracks for the eleven MARSIS basins ranges from 30 to $130 \mathrm{~km}$ (mean $=90 \mathrm{~km}$, standard deviation $\cong 29 \mathrm{~km}$ ). Thus, we estimate the area covered using a cross-track distance of $180 \pm 58 \mathrm{~km}(2 \times$ the mean and standard deviation due to the left/right ambiguity). Orbit segments were limited to those where the spacecraft altitude was $<500 \mathrm{~km}$ because no parabolic echoes have been detected at greater altitudes.

\section{SUPPLEMENTARY FIGURE AND LEGEND}

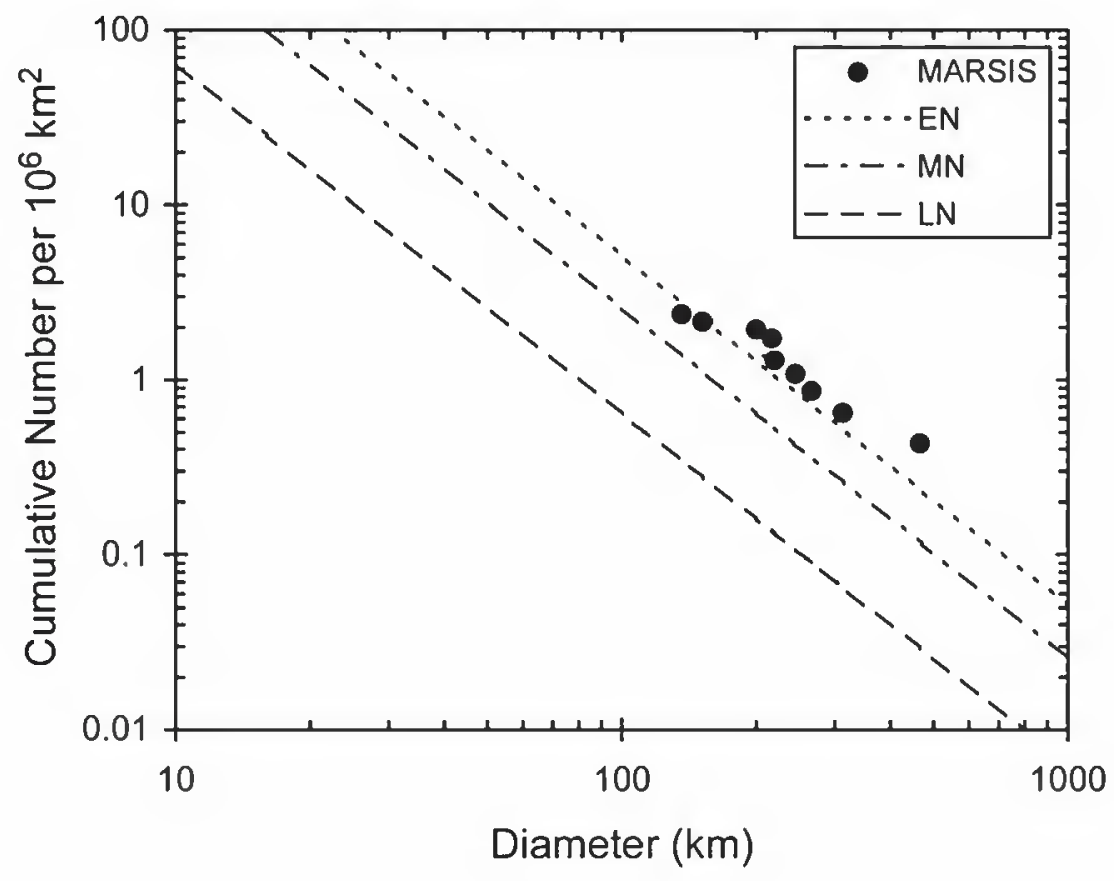

Figure S1. Cumulative frequency plot for MARSIS basins in the northern lowlands of Mars. The dashed lines show the Late Noachian (LN), Middle Noachian (MN), and Early Noachian (EN) boundaries based on crater counts of Tanaka ${ }^{5}$ extrapolated to larger diameters with a -2 power law. Most of the MARSIS basins plot above the Early Noachian boundary. 


\section{REFERENCES}

1. Picardi, G. et al. Radar Soundings of the Subsurface of Mars, Science, 310, 1925-1928 (2005).

2. Safaeinili, A. et al. Impact of Mars ionosphere on orbital radar sounder operation and data processing, Planet. Space Sci., 51, 505-515, 2003.

3. Gurnett, D.L. et al. Radar soundings of the ionosphere of Mars, Science, 310, 1929-1933 (2005).

4. Tanaka, K.L. et al. Resurfacing history of the northern plains of Mars based on geologic mapping of Mars Global Surveyor data, J. Geophys. Res. 108 (E4), doi: 10.1029/2002JE001908 (2003).

5. Tanaka, K.L. The stratigraphy of Mars, Proceed. Lunar Planet. Sci. Conf. 17th, J. Geophys.Res. 91, E139-E158 (1986). 